\title{
Three Ports Versus Four Ports Laporoscopic Cholecystectomy
}

\section{Ahmed Modher Khalaf (FICMS $)^{1}$, Hazim Jabbar Kashtal (FICMS) ${ }^{2}$, Amir Hinbis Masawod (FICMS,CABS) ${ }^{3}$}

${ }^{1}$ College of Medicine, University of Diyala, Baqubah, Iraq

${ }^{2}$ Al_karh General Hospital, Baghdad, Iraq

${ }^{3}$ Al_karh General Hospital, Baghdad, Iraq

Correspondence Address:

Dr. Amir Hinbis Masawod

Al_karh General Hospital, Baghdad, Iraq

email: Amirmas60@gmail.com mobile 009647727786802

Received: 15 September 2020

Revised: 30 September 2020

Accepted: 20 December 2020

Published: 15 April 2021

Diyala Medical Journal 2021:20(1): 17-21

\section{Abstract}

Background: A four trocar laparoscopic cholecystectomy become the standard procedure since the first laparoscopic procedure was reported. But laparoscopic cholecystectomy has gained many steps such as reduction in port number and size.

Objective: To compare Clinical results from three ports versus the traditional four ports in laparoscopic cholecystectomy.

Patients and Methods: A prospective randomized clinical trial of 100 patients was done on those who were admitted for elective laparoscopic cholecystectomy in Baquba teaching hospital, between April 2014 and March 2015, patients were classified into two groups (A) for three ports and (B) for 4 ports. Variables such as, complications, operative time, postoperative pain, nausea, and vomiting were assessed.

Results: One-hundred patients were included in this study, age of them ranged from 18-70 year and a male to female ratio was 1:9. There were no significant differences in demographic data between the two groups. Postoperative pain, analgesic requirements, nausea and vomiting, and hospital stay were slightly more in group B but statistically not significant. Postoperative return to activity was shorter in group A 6.10 versus 7.00 days for group B with $(p=0.021)$ which is statistically significant. There is no difference in the rate of complications.

Conclusion: Three ports laparoscopic cholecystectomy is feasible as an alternative for four ports without any significant complication.

Keywords: Laparoscopy; Cholecystectomy; Postoperative complications 


\section{Introduction}

Laparoscopic procedures aim to achieve a good therapeutic result by minimizing the traumatic and metabolic stress of intervention. Other benefits of surgical procedures include small incision sites, low risks of wound complications, decreased postoperative pain and complications, shorter time of hospital stay, a more quickly return to normal activities, and cost-saving[1].

The basic principles which are the keys to safe surgery:

1.Gain safe entry to the abdominal cavity.

2.Adequate exposure before the operation.

3.Careful dissection with hemostasis. Nonblind clipping or cauterization of bleeding sites.

4.Identification of the anatomy before structure is ligated or divided[2].

It has been agreed that the fourth trocar may not be necessary, and laparoscopic cholecystectomy can be performed safely without it [10]. Studies have reported that 3port LC is technically possible[6].

The more ports were used, however, the higher complications that occurred; bleeding on port site, postoperative pain, lowering cosmetic effect, organ injury caused by inserting the trocar, and incisional hernia[7].

\section{Patients and Methods}

This prospective randomized clinical trial included 100 patients aging from (18-70) years, who were admitted for elective laparoscopic cholecystectomy in the Baquba Teaching Hospital between March, $1^{\text {st }}$ 2012February, $28^{\text {th }} 2013$.

Patients were classified into two groups A for 3 ports and B for 4ports respectively. All patients were operated on under general anesthesia, they were ASA 1 and 2, and they received the same protocol for induction and maintenance with endotracheal intubation.

Exclusion criteria were:

-Acute cholecystitis

-ASA above 2

-Patients with previous upper abdominal operations

The patients received 1 ampoule Dexamethasone $8 \mathrm{mg}$ for decreasing postoperative nausea and vomiting, and $1 \mathrm{~g}$ cefotaxime as a prophylactic antibiotic with the induction of anesthesia. A stomach tube was inserted. Patients were placed supine in reverse Trendelenburg position with tilting to the left side by $30^{\circ}$. In group A the $3^{\text {rd }}$ port was placed according to gallbladder position after visualization by telescope and it was usually located between the positions of the $3^{\text {rd }}$ and $4^{\text {th }}$ port in group $B$.

All patients received the same treatment post operatively, NPO for 6 hours, with maintenance fluid therapy and single dose Tramadol ampoule 100mg intravenously starting 4 hour post operatively.

For comparing postoperative pain we measured through a verbal pain scale, use words to describe the pain. After discharging patients from the hospital they put on oral analgesia. Patients were followed up after one-week for the severity of postoperative pain, postoperative nausea and vomiting, analgesia requirement, and patient's return to activity during.

\section{Statistical analysis}

The Student t-test was used to evaluate the significance of each parameter and Chisquare was used to compare proportions. A 
P-value of $<0.05$ was considered statistically significant. Statistical Package for Social Science (SPSS) Version 18 was used for statistical analysis.

\section{Results}

A hundred patients were included in this study. Age of them ranging from 18- 70 years with mean age \pm SD $39.67 \pm 11.049$, ninety of them were female and 10 male with M: F ratio1:9, shown in Figure (1). Group A for 3 ports and group B for 4 ports.

Table (1): Demographic features

\begin{tabular}{|c|c|c|c|}
\hline Demographic features & $\begin{array}{l}\text { Group A } \\
3 \text { ports }\end{array}$ & $\begin{array}{l}\text { Group B } \\
4 \text { ports }\end{array}$ & P-value \\
\hline Mean age & $40.48 \pm 9.414$ & $38.86 \pm 12.51$ & 0.466 \\
\hline Male- to-female ratio & 18 & $1: 11.5$ & 0.505 \\
\hline Co-morbidity & $11(22 \%)$ & $8(16 \%)$ & 0.444 \\
\hline Family history of gallstone & $15(30 \%)$ & $18(36 \%)$ & 0.523 \\
\hline History of nausea \&vomiting & $17(34 \%)$ & $15(30 \%)$ & 0.668 \\
\hline $\begin{array}{l}\text { History of lower abdominal } \\
\text { operations }\end{array}$ & $13(26 \%)$ & $12(24 \%)$ & 0.235 \\
\hline
\end{tabular}

Table (2): Intraoperative complications

\begin{tabular}{|l||c||c||c||c|}
\hline \hline Complications & Group A & Group B & P.value & Total \\
\hline $\begin{array}{l}\text { Gallbladder perforation } \\
\text { and bile leakage }\end{array}$ & $10(20 \%)$ & $13(26 \%)$ & 0.63 & 23 \\
\hline \hline Port site bleeding & $2(4 \%)$ & $3(6 \%)$ & 0.36 & 5 \\
\hline
\end{tabular}

Regarding operative time, the mean operative time (with SD) was $25.12 \pm 10.2$ min., in group A mean of operative time $\pm \mathrm{SD}$ was $24.18 \pm 10.7 \mathrm{~min}$., while in group B $26.06 \pm 9.6$ min., and $(\mathrm{p}=0.360)$ which is statistically not significant as shown in Table (3).Results of postoperative analgesia requirements both parenteral and oral were slightly more in group B in comparison to group $\mathrm{A}$, but statistically not significant as shown in Table (3). Mean postoperative hospital stays \pm SD was $23.28 \pm 6.5$ hours for group A and 25.44 \pm 8.2 for group B which was more but not significant as shown in Table (3).

Post-operative return to normal activity was earlier in group A $(6.10 \pm 2.2$ versus $7.00 \pm 1.57$ ) days for group $B$ with $\mathrm{p}=0.021$ which is statistically significant as shown in Table (3).

Table (3): Operative and postoperative parameters

\begin{tabular}{|l||c||c||l||}
\hline \hline Operative and Postoperative parameters & Group- A & Group -B & P-value \\
\hline \hline Operative time & $24.18 \pm 10.7$ & $26.06 \pm 9.6$ & 0.360 \\
\hline \hline Analgesia requirements / parenteral & $2.46 \pm 0.64$ & $2.62 \pm 0.6$ & 0.203 \\
\hline \hline Analgesia requirements / oral & $10.26 \pm 5.5$ & $11.74 \pm 5.0$ & 0.165 \\
\hline Postoperative hospital stay & $23.28 \pm 6.5$ & $25.44 \pm 8.2$ & 0.152 \\
\hline Postoperative return to activity & $6.10 \pm 2.2$ & $7.00 \pm 1.57$ & 0.021 \\
\hline
\end{tabular}

Postoperative pain measured within $24 \mathrm{hr}$ and $\mathrm{p}=0.534$ which is statistically not significant. within 1 week was shown in Table(4) with 
Table (4): Postoperative pain within $24 \mathrm{hr}$ and within one-week

\begin{tabular}{|c||c||c|c||c|}
\hline \multirow{2}{*}{ Postoperative pain } & \multicolumn{2}{|c|}{ Within 24hr. } & Within & On-week \\
\cline { 2 - 5 } & Group- A & Group- B & Group- A & Group- B \\
\hline \hline No pain & $2(4 \%)$ & $1(2 \%)$ & $11(22 \%)$ & $9(18 \%)$ \\
\hline \hline Mild & $24(48 \%)$ & $18(36 \%)$ & $28(56 \%)$ & $26(52)$ \\
\hline Moderate & $21(42 \%)$ & $28(56 \%)$ & $10(20 \%)$ & $15(30 \%)$ \\
\hline \hline Severe & $3(6 \%)$ & $3(6 \%)$ & $1(2 \%)$ & $0(0 \%)$ \\
\hline \hline No. & 50 & 50 & 50 & 50 \\
\hline
\end{tabular}

\section{Discussion}

At present widespread use of laparoscopic cholecystectomy world-wide. In laparoscopic surgery, less postoperative pain and early recovery are major goals to had better patient care and cost-effectiveness [8]. Studies demonstrated less postoperative pain was associated with a decrease in either size or number of ports [3]. LC is now often performed with only three ports [6]. In our study, the three-port technique was compared with the standard four-port method in a prospective randomized controlled trial, through comparing clinical outcomes of those two groups in the way of operative time, postoperative pain, analgesic requirements, postoperative nausea and vomiting, hospital stay and patients return to normal activities. The goal was to evaluate its usefulness and its safety, and to see whether it feasible to do 3 ports LC.

The results show that the demographic features of these 2 groups were near the same, and it is also similar in Trichack [6] and Kumar [8]. And this makes the results of the other variables more accurate. Regarding postoperative complication results were near to each other in both groups. We had no bile duct injury and this result similar to the results of Kumar[8]. The results of our present study show that there were slightly more in group B but without significant differences in operating time, the same result was present in a meta-analysis of 5 studies done by Sun et al [10]. The mean operative time was shorter for group A, In Trichak study, the three-port group needs less oral analgesic tablets and injections, but the difference not statistically significant[6].

Postoperative hospital stay was more in group B but not significantly in group $\mathrm{A}$. The introduction of the 3-ports technique improved length of hospital stay, adding costeffective benefit to the procedure; possible causes for this reduction we found a strong correlation between the dosage of opiates consumed and length of hospital stay which may explain this reduction[9].

Regarding postoperative return to normal activity were earlier in group A $6.10 \pm 2.2$ while $7.00 \pm 1.57$ days for group $B$ with $\mathrm{p}=0.021$ which is statistically significant. While in Kumar's study the results were 4.9 versus 5.8 for 3 ports and 4 ports respectively with a $\mathrm{P}=0.16$, which was not significant. Pain is the most common symptom experienced by surgical patients, has historically been poorly evaluated and undertreated. For comparing postoperative pain we measured verbal pain scales, use words to describe the pain. A word such as no pain, mild pain, moderate pain, and severe pain are used to explain pain level[1]. 
Postoperative pain measured within $24 \mathrm{hr}$. and within 1 week postoperatively and compared in both groups, the results show that there was not a significant difference between these two groups, both within 24hr. and within one-week. Postoperative nausea and vomiting is a common complication and results in patient weakness and demoralization, prolonged nausea and vomiting, increase pain levels, and a prolonged hospital stay[11].

\section{Conclusions}

We conclude that 3 ports laparoscopic cholecystectomy is feasible and safe alternative for 4 ports without any significant complication, with the additional advantages of less scar and cosmetic results.

\section{Recommendations}

Three ports could be a standard for laparoscopic cholecystectomy if practiced by surgeons experienced in laparoscopic techniques. We hope that single port LC also will be performed in our country.

\section{References}

[1]Tülün öztürk. Textbook of Advanced laparoscopy .rijeka,Croatia.2011;1.

[2]Douglas O. Olsen and Renee S. Wolfe. Laparoscopic surgery of the abdomen.Springer.2004;87.

[3]Poon CM, Chan KW, Lee DW, et al. Twoport versus four port laparoscopic cholecystectomy. Surg Endosc. 2003;17 (10:( 1624-7.

[4]Cerci C, Tarhan OR, Barut I et al (2007) Three-port versus fourport laparoscopic cholecystectomy. Hepatogastroenterology 54:15.
[5]Welter FH (2006) Laparoscopic cholecystectomy - a never-ending success story? MMW Fortschr Med 148:38.

[6]Trichak S: Three-port vs standard fourport laparoscopic cholecystectomy. Surg Endosc 2003, 17(9):1434-6.

[7]Kaushik R. Bleeding complications in laparoscopic cholecystectomy: incidence, mechanisms, prevention and management. J Minim Access Surg 2010;6:59-65.

[8]Kumar M, Agrawal CS, Gupta RK (2007) Three-port versus standard four-port laparoscopic cholecystectomy: a randomized controlled clinical trial in a community-based teaching hospital in eastern Nepal. JSLS 11:358.

[9]Al-Azawi D., Houssein N. , Rayis A.,McMahon D., Hehir D. J. Three-port versus four-port laparoscopic cholecystectomy in acute and chronic cholecystitis. BMC Surgery. 2007; 7:8.

[10] Sun S.,Yang K., Gao M.,He X. , Tian J., Ma B. Three-Port Versus Four-Port Laparoscopic Cholecystectomy:MetaAnalysis of Randomized Clinical Trials. World J Surg. 2009; 33:1904-8.

[11]Alistair Pace and Nicholas C.M. Armitage. Textbook of Baily and loves,short practice of surgery 25th edition. Edward Arnold. 2008; 263.

[12]Koo Eun Jung et al. Review of 100 cases of single port laparoscopic Cholecystectomy. J Korean Surg Soc 2012;82: 179-184. 